\title{
Relationship between General Health Behaviors and Oral Health Behaviors in 2015-2016 NHANES Adult Population
}

\author{
Rami Saadeh ${ }^{1,2}$ Irene Bober-Moken ${ }^{2}$ Suman Challa ${ }^{2}$ \\ ${ }^{1}$ Department of Public Health and Community Medicine, Faculty \\ of Medicine, Jordan University of Science and Technology, Irbid, \\ Jordan \\ 2 Department of Comprehensive Dentistry, School of Dentistry, \\ University of Texas Health Sciences Center at San Antonio, San \\ Antonio, Texas, United States
}

\begin{abstract}
Address for correspondence Rami Saadeh, BDS, MSPH, PhD, Department of Public Health and Community Medicine, Faculty of Medicine, Jordan University of Science and Technology, Irbid, Jordan 22110 (e-mail: rasaadeh@just.edu.jo).
\end{abstract}

Eur J Dent 2019;13:405-412

Abstract


Keywords
- general health
behaviors
- oral health behaviors
- adults
- National Health and

Nutrition Examination
Survey
- risk behaviors

Objectives The aim of this study was to examine the relationship between general health behaviors and oral health behaviors in adults who participated in the interview component of the National Health and Nutrition Examination Survey (NHANES) of 2015 to 2016.

Materials and Methods This was a cross-sectional study design of a national data set that included 5,992 adults who represented a sample of civilian, noninstitutionalized US population.

Statistical Analysis Chi-squared test of independence was used to describe the relationship of demographic information with oral health behaviors of participants. Multivariate logistic regression was used to determine the association between general and oral health behaviors.

Results More than half (53.6\%) of the participants had seen a dentist in the past 12 months and the main reason for that visit was for a regular checkup, cleaning, or examination. More than one-quarter (28.7\%) reported visiting a dentist because something was hurting or bothering them. Most respondents (63.4\%) reported being hardly ever or never having been embarrassed by their mouth condition. Age at one's first sexual encounter, having a new sexual partner, mental health counseling, moderate-intensity sports, and computer use were significantly associated with positive oral health behaviors.

Conclusions For maximum effectiveness, health promotion efforts should target risk behaviors common to both oral and general health.

\section{Introduction}

General health is associated with the health of all organs of the body, one of which is the mouth. The mouth and body are intertwined; diseases of the mouth can adversely affect an individual's overall health and quality of life. ${ }^{1}$ Diseases of the cardiovascular system, immune system, diabetes, as well as neurological and congenital disorders are linked to the health of the oral cavity..$^{2-5}$ Likewise, diseases of the mouth, such as dental infections and teeth loss, can adversely affect chronic diseases such as diabetes, kidney disease, and cardiovascular disease.,46 The connection between the oral health and general health is believed to be due to common risk factors and/or behaviors, for example, smoking, alcohol use, physical activity, and maintaining proper weight. 
Samnieng et al, in a geriatric population, found that general health practices were associated with the clinical oral health status such as the number of teeth present, decayed teeth, periodontal disease, oral malodor, and salivary flow rate. ${ }^{7}$ Petersen et al found that adolescents with high levels of preventive oral health practices also demonstrated general health-promoting behaviors. ${ }^{8}$ This is supported by Tada and Maksukubo's study that found tooth-brushing frequency was the most predictive indicator of general health behavior. ${ }^{9}$

Since there are common risk factors that are directly or indirectly related to poor oral health and poor general health, ${ }^{7}$ it is crucial to examine these factors and the nature of their relationship with each other. One of the benefits of understanding the relationship between general and oral health behaviors is to manage poor behaviors to improve other behaviors related to them, thereby reducing unfavorable general and oral health conditions. ${ }^{7}$ Another benefit is costeffectiveness. It is more cost-effective to integrate oral health promotion into general health promotion than to target single oral health diseases. ${ }^{8}$ Hence, if certain health behaviors are strongly correlated, it will be more efficient to target all such behaviors in similar interventional or promotional programs, which in turn can also result in positive outcomes for nontargeted behaviors. Similarly, if associations between certain risk factors are weak, then changes in one behavior is not expected to cause changes in all other behaviors., ${ }^{8,10}$

Therefore, this study aims to examine the relationship between general health behaviors and oral health behaviors in adults who participated in the National Health and Nutrition Examination Survey (NHANES) of 2015 to 2016.

\section{Materials and Methods}

This project used the 2015-2016 NHANES data set focusing on the findings of the 5,992 adults ( $\geq 18$ years old) who participated in the home interview. NHANES is a cross-sectional assessment of the health and nutrition status of US children and adults conducted every 2 years. It uses stratified, multistage probability sampling, to produce a representative sample of the civilian, noninstitutionalized US population. ${ }^{11}$ There is an oversampling of low-income persons, African Americans, Mexican Americans, adolescents aged 12 to 19 years, and persons 60 years and older.

The data are accessible to the public through the Centers for Disease Control and Prevention NHANES data Web site. ${ }^{12}$ This project was exempted from the institutional review board review because it used anonymous secondary data set.

NHANES has a complex design that employed unequal chances of selection for the respondents by race and Hispanic origin, income, age, and sex. Each respondent in the NHANES sample is given a case weight, which estimated the number of people in the target population that each person represents.

Variables describing oral health behavior were selected as dependent variables: time of last visit to a dentist, the main reason for that visit, embarrassment of the mouth condition in the previous year, and flossing frequency. Each of these variables was rescaled in the multivariate regression analysis because there were many scales (i.e., many answer choices) in each of these variables that affected the analysis and the interpretation of the results. Therefore, time to last visit to a dentist was rescaled from 7 scales to 4 , embarrassment of the mouth was rescaled from 5 scales to 3 , and flossing frequency, which was a continuous variable, was recategorized into a categorical variable of 2 scales; flossing less than three times per week and flossing three or more times per week.

Health care utilization (i.e., health facility used and mental therapy), physical activity, sexual behavior, and tobacco use were selected as independent variables. Six demographic variables were considered covariates: gender, age, race, citizenship status, level of education, and ratio of family income. All demographic variables were categorical except age, which is a continuous variable. Individuals 80 years and older are top coded at 80 years of age. In the multivariate regression analysis, age is categorized into four categories: adults $<30$ years old, 30 to 44 years old, 45 to 64 years old, and $\geq 65$ years old. NHANES uses the Department of Health and Human Services poverty guidelines to calculate the ratio of family income to poverty ${ }^{13}$ and scaled it 1 to 5 . The ratio was calculated by dividing family (or individual) income by the poverty guidelines specific to the survey year. Values at or above 5.00 were coded as $5.00 .^{14}$

Logistic regression was used to examine the relationship of demographic data and the dependent variables; statistically significant findings were controlled for in all analyses to rule out the effect of demographics on oral health behaviors. The data were weighted according to population distributions of different demographic groups and complex sampling methods were used to adjust sampling biases.

Descriptive statistics were used to describe the sample. Chi-squared independent test was used to assess the association of demographic data with oral health behaviors. Binary logistics regression was used to examine the association of independent variables with flossing frequency. Multinomial logistic regression was used to examine the associations of independent variables with the categorical dependent variables (i.e., time to last visit to a dentist, main reason for a visit, and previous embarrassment of the mouth). SPSS Statistical Software Version 23 (IBM Corp., Armonk, N.Y., United States) was used to perform the analysis. Bonferroni correction was used to determine adjusted $p$-values for multiple hypothesis testing. A $p$-value of 0.05 or less was considered statistically significant.

\section{Results}

There were 5,992 adults, and approximately $83 \%$ of them were US citizens. There were 2,887 (48.2\%) men and 3,105 (51.8\%) women. Age of participants ranged from 18 to 80 (or older) years, with a mean age of $48.12( \pm 18.52)$ years. More than half of the sample population consisted of non-Hispanic whites $(1,914$ or $31.9 \%$ ) or non-Hispanic blacks (1,265 or $21.1 \%)$. The remaining race/ethnicity distribution was Mexican Americans (1,064 or $17.8 \%$ ), other Hispanics (798 or $13.3 \%$ ), non-Hispanic Asians (726 or $12.1 \%$ ), and other races (225 or $3.8 \%$ ). 
Less than half (43.4\%) of the participants had a high school diploma or less, $28 \%$ had some college, and $23 \%$ had college or graduate degrees. The mean ratio of family income to poverty was $2.4( \pm 1.6)$. The association of demographic data with oral health behavior is seen in - Table 1 .

More than half of participants (52.5\%) visited a doctor's clinic or a health maintenance organization of medical care, around one-quarter $(24.2 \%)$ visited a clinic or a health center, and the rest visited a hospital or another place. Less than $10 \%$ (8.8\%) reported receiving mental health therapy.

Just more than one-fifth (20.7\%) of participants reported having vigorous work activity with a mean of 4.03 days/week $( \pm 1.83)$, and $37.7 \%$ had moderate work activity with a mean of 4.2 days/week $( \pm 1.80)$. Of those who exercised, $26 \%$ had vigorous recreational activity with a mean of 3.3 days/week $( \pm 1.57)$, and $\sim 41 \%$ had moderate recreational activity with a mean of 3.5 days/week $( \pm 1.80)$. Twenty-three percent of participants reported that they walk or use bicycle, with a mean of 4.6 days/week $( \pm 1.95)$.

Approximately $67 \%$ of participants spent 1 to 5 hours/day watching TV or playing video games in the last 30 days, and $16.5 \%$ reported more than 5 hours/day. Forty-five percent reported spending 1 to 5 hours/day using a computer in the last 30 days with around 35\% never having used a computer in the last 30 days. Sixty percent did not respond to the question regarding tobacco use. Of the $40 \%$ who answered, $34.4 \%$ reported smoking daily, $18 \%$ used e-cigarettes, and $14 \%$ used smokeless tobacco, and $~ 55 \%$

Table 1 The relationship of demographics with oral health behaviors in US adults aged 18 to $\geq 80$ years ( $n=5,992)$ (NHANES 2015-2016, weighted)

\begin{tabular}{|c|c|c|c|c|c|c|c|c|c|c|c|c|}
\hline \multirow{2}{*}{\begin{tabular}{|l|} 
\\
Last \\
visit \\
to a \\
dentist
\end{tabular}} & \multirow{2}{*}{\begin{tabular}{|c|}
$\begin{array}{c}\text { Gender } \\
(\%)\end{array}$ \\
$\mathrm{M} ; \mathrm{F}$
\end{tabular}} & \multicolumn{2}{|c|}{ Age (\%) } & \multicolumn{2}{|c|}{ Citizenship (\%) } & \multicolumn{3}{|c|}{ Education ${ }^{\mathrm{a}}(\%)$} & \multicolumn{2}{|c|}{$\operatorname{Race}^{\mathrm{b}}(\%)$} & \multicolumn{2}{|c|}{ Family income ratio (\%) } \\
\hline & & \multirow[t]{5}{*}{$p<0.001$} & $\begin{array}{l}<30 ; 30-45 \\
45-65 ;>65\end{array}$ & \multirow[t]{5}{*}{$p<0.001$} & $\mathrm{Y}, \mathrm{N}$ & \multirow[t]{5}{*}{$p<0.001$} & $1 ; 2 ; 3$ & \multirow[t]{5}{*}{$p<0.001$} & $\mathrm{H} ; \mathrm{W} ; \mathrm{B} ; \mathrm{A} ; \mathrm{O}$ & \multirow[t]{5}{*}{$p<0.001$} & $\begin{array}{l}<1 ; 1-2.5 \\
2.5-4 ; 4-5\end{array}$ & \multirow[t]{5}{*}{$p<0.001$} \\
\hline $\begin{array}{l}<1 \mathrm{y} \\
\text { ago }\end{array}$ & $45 ; 55$ & & $\begin{array}{l}19.0 ; 23.6 ; \\
35.5 ; 21.8\end{array}$ & & $92.8,7.2$ & & $\begin{array}{l}29 ; 30.8 ; \\
40.2\end{array}$ & & $\begin{array}{l}12 ; 67.9 ; 0.2 ; \\
6.4 ; 3.6\end{array}$ & & $\begin{array}{l}9.6 ; 23.4 ; 19.8 \\
47.2\end{array}$ & \\
\hline $\begin{array}{l}1-3 y \\
\text { ago }\end{array}$ & $50.4 ; 49.6$ & & $\begin{array}{l}27.6 ; 27.0 \\
31.4 ; 14.0\end{array}$ & & $\begin{array}{l}88.4 \\
11.6\end{array}$ & & $\begin{array}{l}43.3 ; 35.3 ; \\
21.4\end{array}$ & & $\begin{array}{l}20.1 ; 56 ; \\
14.9 ; 5 ; 4\end{array}$ & & $\begin{array}{l}\text { 19.2; } 32.6 \\
23.8 ; 24.4\end{array}$ & \\
\hline $\begin{array}{l}\geq 3 \mathrm{y} \\
\text { ago }\end{array}$ & $53.7 ; 46.3$ & & $\begin{array}{l}18.2 ; 26.8 ; \\
34.8 ; 20.2\end{array}$ & & $\begin{array}{l}88.4 \\
11.6\end{array}$ & & $\begin{array}{l}50.2 ; 32.8 ; \\
16.9\end{array}$ & & $\begin{array}{l}19 ; 61.1 ; \\
11.6 ; 4.4 ; 4\end{array}$ & & $\begin{array}{l}22 ; 40 ; 18.1 ; \\
19.9\end{array}$ & \\
\hline \begin{tabular}{|l|} 
Never \\
been \\
to a \\
dentist
\end{tabular} & $69.6 ; 30.4$ & & $\begin{array}{l}33.9 ; 36.7 ; \\
19.9 ; 9.4\end{array}$ & & 37,63 & & $\begin{array}{l}76.2 ; 14.7 ; \\
9.1\end{array}$ & & $\begin{array}{l}53.7 ; 10.3 ; \\
19.9 ; 15.5 ; \\
0.6\end{array}$ & & $\begin{array}{l}50.2 ; 36.8 \\
6.4 ; 6.5\end{array}$ & \\
\hline \multicolumn{2}{|c|}{$\begin{array}{l}\text { Main reason to } \\
\text { visit }\end{array}$} & \multirow[t]{5}{*}{$p=0.634$} & & \multirow[t]{5}{*}{$p<0.001$} & & \multirow[t]{5}{*}{$p<0.001$} & & \multirow[t]{5}{*}{$p<0.001$} & & \multirow[t]{5}{*}{$p<0.001$} & & \multirow[t]{5}{*}{$p<0.001$} \\
\hline $\begin{array}{l}\text { Went } \\
\text { in on } \\
\text { own for } \\
\text { checkup }\end{array}$ & $46.8 ; 53.2$ & & $\begin{array}{l}22.5 ; 27.9 \\
32.3 ; 17.3\end{array}$ & & $91.5,8.5$ & & $\begin{array}{l}28.5 ; 31.5 ; \\
40\end{array}$ & & $\begin{array}{l}13.5 ; 66.9 ; \\
10 ; 6.5 ; 3.2\end{array}$ & & $\begin{array}{l}9.823 .919 .7 \\
46.6\end{array}$ & \\
\hline $\begin{array}{l}\text { Was } \\
\text { called } \\
\text { in for a } \\
\text { checkup }\end{array}$ & $48.8 ; 51.2$ & & $\begin{array}{l}20.2 ; 23.5 ; \\
37.2 ; 19.0\end{array}$ & & $96.1,3.9$ & & $\begin{array}{l}24.9 ; 31.7 \\
43.5\end{array}$ & & $\begin{array}{l}8.7 ; 69.8 ; \\
9.1 ; 5.6 ; 6.8\end{array}$ & & $\begin{array}{l}9.4 ; 18.2 ; 22.6 ; \\
49.8\end{array}$ & \\
\hline $\begin{array}{l}\text { Some- } \\
\text { thing } \\
\text { was } \\
\text { hurting }\end{array}$ & $50 ; 50$ & & $\begin{array}{l}17.6 ; 23.7 ; \\
37.7 ; 21.0\end{array}$ & & $\begin{array}{l}89.7 \\
10.3\end{array}$ & & $\begin{array}{l}51.5 ; 34 ; \\
14.5\end{array}$ & & $\begin{array}{l}17.7 ; 58.1 ; \\
15.2 ; 4.4 ; 4.6\end{array}$ & & $\begin{array}{l}22 ; 37.9 ; 19.3 ; \\
20.8\end{array}$ & \\
\hline $\begin{array}{l}\text { Treat- } \\
\text { ment of } \\
\text { a condi- } \\
\text { tion }\end{array}$ & $48.5 ; 51.5$ & & $\begin{array}{l}18.2 ; 16.9 ; \\
37.4 ; 27.4\end{array}$ & & $\begin{array}{l}88.2 \\
11.8\end{array}$ & & $\begin{array}{l}43.2 ; 32.2 ; \\
24.6\end{array}$ & & $\begin{array}{l}20.7 ; 61.2 ; \\
10.2 ; 4.9 ; 3\end{array}$ & & $\begin{array}{l}\text { 19.2; } 37.0 ; \\
22.5 ; 21.3\end{array}$ & \\
\hline \multicolumn{2}{|c|}{$\begin{array}{l}\text { Embarrassment of } \\
\text { the mouth in the } \\
\text { last year }\end{array}$} & \multirow[t]{4}{*}{$p=0.005$} & & \multirow[t]{4}{*}{$p=0.054$} & & \multirow[t]{4}{*}{$p=0.433$} & & \multirow[t]{4}{*}{$p<0.001$} & & \multirow[t]{4}{*}{$p<0.001$} & & \multirow[t]{4}{*}{$p<0.001$} \\
\hline Often & $41.1 ; 48.9$ & & $\begin{array}{l}\text { NA; } 27.6 ; \\
52.1 ; 20.3\end{array}$ & & $\begin{array}{l}89.5 \\
10.5\end{array}$ & & $\begin{array}{l}51.2 ; 36.3 ; \\
12.5\end{array}$ & & $\begin{array}{l}19.8 ; 58.9 ; \\
15.4 ; 1.6 ; 4.3\end{array}$ & & $\begin{array}{|lll|}29.4 & 41.5 & 14.8 \\
14.2 & \end{array}$ & \\
\hline $\begin{array}{l}\text { Occa- } \\
\text { sionally }\end{array}$ & $40.6 ; 59.4$ & & $\begin{array}{l}\text { NA; } 32 ; \\
43.4 ; 24.6\end{array}$ & & $91.9,8.1$ & & $\begin{array}{l}40.4 ; 39.9 ; \\
19.7\end{array}$ & & $\begin{array}{l}14.8 ; 67.2 \\
10.2 ; 3 ; 4.8\end{array}$ & & $\begin{array}{l}17.2 ; 33.6 \\
25.3 ; 23.9\end{array}$ & \\
\hline $\begin{array}{l}\text { Never/ } \\
\text { hardly }\end{array}$ & $49.1 ; 50.9$ & & $\begin{array}{l}\text { NA; } 32 ; \\
42.3 ; 25.6\end{array}$ & & $90.8,, 9.2$ & & $\begin{array}{l}33.2 ; 29.9 \\
36.9\end{array}$ & & $\begin{array}{l}13.3 ; 66.6 ; \\
10.3 ; 6.4 ; 3.4\end{array}$ & & $\begin{array}{l}\text { 10.6; } 25.3 ; \\
19.7 ; 44.4\end{array}$ & \\
\hline \multicolumn{2}{|c|}{ Flossing times/wk } & \multirow[t]{2}{*}{$p<0.001$} & & \multirow[t]{2}{*}{$p<0.001$} & & \multirow[t]{2}{*}{$p<0.001$} & & \multirow[t]{2}{*}{$p<0.001$} & & \multirow[t]{2}{*}{$p=0.095$} & & \multirow[t]{2}{*}{$p<0.001$} \\
\hline $\begin{array}{l}\geq 3 \\
\text { times }\end{array}$ & $41.5 ; 58.5$ & & $\begin{array}{l}\text { NA; } 27.4 ; \\
46.3 ; 26.3\end{array}$ & & $92.5,7.2$ & & $\begin{array}{l}27.6 ; 32.8 ; \\
39.6\end{array}$ & & $\begin{array}{l}\text { 13.3; 66.9; } \\
9.8 ; 6.3 ; 3.7\end{array}$ & & $\begin{array}{lll}10.1 & 24.1 & 18.7 \\
47.1 & & \end{array}$ & \\
\hline
\end{tabular}

Abbreviations: chi-squared test of independence was used in the analysis; NA, not available.

aEducation: 1 is high school graduate or less, 2 is some college, and 3 is college graduate or higher.

bRace: $\mathrm{H}$ is Hispanic, $\mathrm{W}$ is white, $\mathrm{B}$ is Black, $\mathrm{A}$ is Asian, and $\mathrm{O}$ is other. 
reported never smoking. Those who tried to quit smoking were $\sim 55 \%$.

Among those who shared information about their sexual behavior, $5 \%$ reported having sex for the first time when they were younger than 12 years, and 52\% between 12 and 18 years old. Those who reported using protection when performing oral sex were $8 \%$, and $82.4 \%$ reported that they never used protection. In addition, $18 \%$ reported having a new sexual partner each year, and $45 \%$ reported that they never used condom when having sex, and about one-quarter reported using condoms all the time when having sex.

More than half of the study sample participants had seen a dentist in the previous year (53.6\%), and only $2.4 \%$ had never been to a dentist. Twenty-seven percent had not seen a dentist for more than a year but less than 5 years, and approximately $16 \%$ reported their last dental visit being more than 5 years ago. The most common reason for the last visit to a dentist was going in for checkup, examination, or cleaning (47.3\%). More than one-quarter (28.7\%) reported visiting a dentist because something was hurting or bothering them. The majority of respondents (63.4\%) reported being hardly ever or never having been embarrassed by their mouth condition, less than $20 \%$ were often or occasionally embarrassed, and $20.9 \%$ did not report anything. Approximately $44 \%$ reported flossing less than three times per week, $35 \%$ reported more than three times a week, and 21\% did not report anything.

\section{Multivariate Analysis}

Participants who reported having a new sexual partner each year were three times more likely to visit a dentist compared with those who did not have new sexual partners each year (-Table 2). Having sex at an earlier age was significantly associated with having visited a dentist because something was bothering or hurting.

Table 2 Relationship of sexual behavior with oral health behaviors

\begin{tabular}{|c|c|c|c|}
\hline & OR & $p$-Value ${ }^{a}$ & $95 \% \mathrm{Cl}$ \\
\hline \multicolumn{4}{|l|}{ Time since last visit to a dentist ${ }^{\mathrm{a}}$} \\
\hline \multicolumn{4}{|l|}{ Less than a year ago } \\
\hline Have new partner each year & 3.06 & 0.036 & $1.08-8.67$ \\
\hline Didn't have a new partner each year & 1 & & \\
\hline \multicolumn{4}{|l|}{ More than a year but not more than 3 y ago } \\
\hline Have new partner each year & 3.09 & 0.036 & $1.06-9.02$ \\
\hline Didn't have a new partner each year & 1 & & \\
\hline \multicolumn{4}{|l|}{ More than 3 y ago } \\
\hline Have new partner each year & 3.59 & 0.021 & $1.21-10.63$ \\
\hline Didn't have a new partner each year & 1 & & \\
\hline \multicolumn{4}{|l|}{ Main reason of the last visit to a dentist ${ }^{\mathrm{b}}$} \\
\hline \multicolumn{4}{|l|}{ Something was wrong bothering or hurting } \\
\hline Had sex when was 12 y or younger & 2.80 & 0.002 & $1.46-5.38$ \\
\hline Had sex when was $12-18$ y old & 1.81 & 0.001 & $1.28-2.55$ \\
\hline Had sex at 18 y or older & 1 & & \\
\hline \multicolumn{4}{|c|}{ Went for treatment of a condition that dentist discovered earlier } \\
\hline Have new partner each year & 0.462 & 0.028 & $0.232-0.921$ \\
\hline Didn't have a new partner each year & 1 & & \\
\hline \multicolumn{4}{|l|}{ Embarrassment of the mouth ${ }^{c}$} \\
\hline \multicolumn{4}{|l|}{ Often embarrassed } \\
\hline Had sex when was 12 y or younger & 3.36 & 0.005 & $1.45-7.79$ \\
\hline Had sex at 18 y or older & 1 & & \\
\hline \multicolumn{4}{|l|}{ Occasionally embarrassed } \\
\hline Use condom half of the time & 0.245 & 0.019 & $0.075-0.797$ \\
\hline Use condoms more than half of the time & 0.255 & 0.015 & $0.085-0.768$ \\
\hline Use condoms always & 1 & & \\
\hline
\end{tabular}

Abbreviations: $\mathrm{Cl}$, confidence interval; OR, odds ratio.

Note: Only significant variables are included.

a"Never have been to a dentist" is the reference group for time since the last visit to a dentist.

"Went in on own for checkup, examination, or cleaning" is the reference group for main reason of the last visit.

"Hardly ever or never embarrassed of the mouth" is the reference group for embarrassment of the mouth. 
Regarding the relationship of health care utilization with oral health behaviors, two variables were used to predict oral health behaviors: the facility that was usually used for health care and mental health counseling. None of the associations between the health care facilities used and oral health behaviors were statistically significant. Mental health counseling was significantly associated with timing of the last dental visit. Those having had mental health counseling were more likely to have visited a dentist within the previous year (odds ratio [OR]: 5.013; 95\% confidence interval [CI]: 1.006-24.971, $p=0.049$ ) or have visited a dentist more than a year ago but less than 3 years ago (OR: 6.984; 95\% CI: 1.396-34.926, $p=0.018$ compared with those who never visited a dentist. Furthermore, they were more likely to visit a dentist for treatment of a condition that was discovered earlier (OR: $1.78 ; 95 \% \mathrm{CI}: 1.16-2.71, p=0.008$ ) and were more likely to be occasionally or often embarrassed than never embarrassed (OR: 1.70 ; 95\% CI: $1.0-2.90, p=0.049$ ) and (OR: $2.22 ; 95 \% \mathrm{CI}$ : $1.44-3.43, p<0.0001$ ), respectively. Flossing frequency was not statistically significant.

As seen in - Table 3, computer use was statistically significant with the timing of the last dental visit, being embarrassed of their mouth condition or flossing frequency. Other sedentary physical activities (i.e., watching TV or playing video games) were not statistically significant.

Those doing moderate-intensity sports, fitness, or recreational activities during the week were more likely to have seen a dentist within the last year, were less likely to have visited a dentist because something was bothering or hurting them, and were more likely to floss their teeth more than three times per week. Moderate-intensity activity at work was associated with being embarrassed by their

Table 3 Relationship of physical activity with oral health behaviors

\begin{tabular}{|c|c|c|c|}
\hline & OR & $p$-Value & $95 \% \mathrm{Cl}$ \\
\hline \multicolumn{4}{|l|}{ Time since last visit to a dentist ${ }^{\mathrm{a}}$} \\
\hline \multicolumn{4}{|l|}{ Less than a year ago } \\
\hline Moderate recreational activity & 1.62 & 0.042 & $1.02-2.57$ \\
\hline No moderate recreational activity & 1 & 0.009 & $1.23-4.40$ \\
\hline Use computer $1 \mathrm{~h}$ or less & 2.33 & 0.001 & $1.69-7.28$ \\
\hline Use computer $2-4 \mathrm{~h}$ & 3.05 & & \\
\hline Doesn't use computers & 1 & & \\
\hline \multicolumn{4}{|l|}{ More than a year but less than 3 y ago } \\
\hline Use computer $2-4 \mathrm{~h}$ & 3.68 & 0.001 & $1.76-7.7$ \\
\hline Doesn't use computers & 1 & & \\
\hline \multicolumn{4}{|l|}{ More than 3 y ago } \\
\hline Use computer $1 \mathrm{~h}$ or less & 2.02 & 0.031 & $1.07-3.85$ \\
\hline Use computer $2-4 \mathrm{~h}$ & 2.92 & 0.005 & $1.39-6.07$ \\
\hline Doesn't use computers & 1 & & \\
\hline \multicolumn{4}{|c|}{ Main reason of the last visit to a dentist ${ }^{b}$} \\
\hline \multicolumn{4}{|c|}{ Something was wrong, bothering or hurting } \\
\hline Vigorous work activity & 1.56 & \multirow[t]{2}{*}{$<0.0001$} & \multirow[t]{2}{*}{$1.24-2.06$} \\
\hline No vigorous work activity & 1 & & \\
\hline Walk or bike & 0.79 & \multirow[t]{2}{*}{0.036} & \multirow[t]{2}{*}{$0.63-0.98$} \\
\hline Doesn't walk or bike & 1 & & \\
\hline Moderate recreational activity & 0.74 & \multirow[t]{2}{*}{0.003} & \multirow[t]{2}{*}{$0.601-0.902$} \\
\hline No moderate recreational activity & 1 & & \\
\hline \multicolumn{4}{|c|}{ Embarrassment of the mouth in the last year ${ }^{c}$} \\
\hline \multicolumn{4}{|l|}{ Often embarrassed } \\
\hline Moderate work activity & 1.38 & \multirow[t]{2}{*}{0.046} & \multirow[t]{2}{*}{$1.01-1.90$} \\
\hline No moderate work activity & 1 & & \\
\hline Vigorous recreational activity & 0.63 & \multirow[t]{2}{*}{0.049} & \multirow[t]{2}{*}{$0.40-0.99$} \\
\hline No vigorous recreational activity & 1 & & \\
\hline Use computer 5 h or more & 1.93 & \multirow[t]{2}{*}{0.026} & \multirow[t]{2}{*}{$1.08-3.43$} \\
\hline Doesn't use computers & 1 & & \\
\hline
\end{tabular}


Table 3 continued

\begin{tabular}{|c|c|c|c|}
\hline & OR & $p$-Value & $95 \% \mathrm{Cl}$ \\
\hline \multicolumn{4}{|l|}{ Occasionally embarrassed } \\
\hline Moderate work activity & 1.65 & \multirow[t]{2}{*}{0.009} & \multirow[t]{2}{*}{$1.31-2.40$} \\
\hline No moderate work activity & 1 & & \\
\hline Use computer $2-4 \mathrm{~h}$ & 1.7 & 0.015 & $1.11-2.60$ \\
\hline Use computer $5 \mathrm{~h}$ or more & 2.16 & \multirow[t]{2}{*}{0.018} & \multirow[t]{2}{*}{$1.14-4.11$} \\
\hline Doesn't use computers & 1 & & \\
\hline \multicolumn{4}{|c|}{ Flossing more than three times per week } \\
\hline Moderate recreational activity & 1.36 & \multirow[t]{2}{*}{0.003} & \multirow[t]{2}{*}{$1.11-1.66$} \\
\hline No moderate recreational activity & 1 & & \\
\hline Use computer $1 \mathrm{~h}$ or less & 1.33 & \multirow[t]{2}{*}{0.014} & \multirow[t]{2}{*}{$1.06-1.66$} \\
\hline Doesn't use computers & 1 & & \\
\hline
\end{tabular}

Abbreviations: $\mathrm{Cl}$, confidence interval; OR, odds ratio.

Note: Only significant variables are included.

a"Never been to a dentist" is the reference group for time since last visit to a dentist.

b"Went in on own for checkup, examination, or cleaning" is the reference group for main reason of the last visit.

"Hardly ever or never embarrassed of the mouth" is the reference group for embarrassment of the mouth.

d"Flossing less than three times/week" is the reference group for flossing times.

mouth's condition. - Table 3 summarizes the significant associations.

Trying to quit smoking was the only significant predictor of the relationship between tobacco use and oral health behaviors. Those who tried to quit smoking were less likely to have visited a dentist because something was bothering or hurting them compared with those who never tried to quit smoking (OR: 0.64; 95\% CI: 0.42-0.96, $p=0.031$ ). Moreover, they were more likely to be often embarrassed by the condition of their mouth (OR: 1.64; 95\% CI: 1.03-2.74, $p=0.042$ ).

\section{Discussion}

NHANES data show that participants have generally healthy oral health practices, including regular visits to the dentist for regular checkup, cleaning, or examination without the need to be reminded by the dental office. This positive attitude of maintaining regular dental checkups can be attributed to having health insurance or a higher socioeconomic status. This finding is consistent with studies conducted outside the United States. ${ }^{2,15-17}$ Unfortunately, NHANES data in this 2-year wave did not indicate if dental insurance was included in the participants' overall health insurance coverage. However, having dental coverage does not necessary indicate receipt of dental care. The Medical Expenditure Panel Survey, in 2004, revealed that only $57 \%$ of those having private dental coverage had visited a dental clinic compared with $32 \%$ of those having public dental coverage had visited a dental clinic, and only $27 \%$ of those with no dental coverage had visited a dental clinic. ${ }^{18}$ The fact that some study participants in this sample did not visit a dentist in the last 5 years, some had never visited a dentist, and some visited a dentist only when they had pain or discomfort, suggests that such participants might have difficulty in accessing oral health care, had a negative attitude toward health, or both.
It is not easy to predict reasons of poor oral health behaviors. However, studies in different populations, including Korean, Japanese, Brazilian, Thai, Chinese, Turkish, and the US populations, ${ }^{4,7,8,19-22}$ have shown that poor oral health behaviors are significantly associated with poor general health behaviors. Although there are few resources to explain the connection between the two, health theories were insightful. Hollister and Anema reviewed several health theories and their possible application to oral health, ${ }^{10}$ and Dumitrescu et al tested five social-cognitive models to explain predictors of personal oral health behaviors and intentions to improve them..$^{23}$ Conclusions of these studies and others ${ }^{24,25}$ showed that health beliefs significantly affect oral health behaviors.

The relationship between demographic data and oral health behaviors indicates that an individual's demographic background significantly affects their oral health behaviors, which is consistent with many studies and national reports. ${ }^{28,17,20,22,26,27}$ General health behaviors have also been shown to have significant relationships with an individual's demographics. ${ }^{17,20,28}$ Therefore, controlling for demographic data in the analysis decreased the number of significant associations between independent and dependent variables, yet some associations were still statistically significant.

Results of the examined associations in this study were not always as expected when compared with other studies. For example, the association of age at one's first sexual encounter with the main reason of visiting a dentist, the association of mental health counseling with time since the last visit to a dentist and with embarrassment of mouth, and the association of sedentary activities with being embarrassed by the condition of mouth indicated that better or less risky health behaviors are associated with better oral health behaviors and vice versa, which were consistent with findings in other studies. ${ }^{8,9,17,27}$ On the other hand, there are possible explanations for unexpected associations. Those who have a new 
partner each year might be concerned about the medical consequences of their continuous new relationships that can result in a disease transmission and, therefore, seek medical care regularly, including oral health care. ${ }^{29}$ Another explanation, at least among women, could be the perceived importance of needing good oral health to attract a significant other. Studies have shown that women were more interested in their physical appearance and the use of preventive and dental care services than men. ${ }^{27,30}$ Another unexpected finding was the association of computer use with positive oral health behaviors. However, the extended use of computers in this adult population may be related to employment opportunities in jobs associated with a higher socioeconomic status; the latter may usually be associated with a healthier life style. Computer and internet use influencing oral health behaviors and health status was reported among Korean adolescents. ${ }^{31,32}$

Inconsistency is also found among studies. For example, Jiang et al found that physical activity and sedentary activities (i.e., watching television, playing computer games) were weakly associated with dental health status and needs in Chinese urban adolescents. ${ }^{33}$ However, Coulter et al reported a strong association of oral health with mental and physical health in a nationally representative sample of HIV-infected persons receiving medical care, ${ }^{34}$ which is in accordance with what Petersen et al reported that vigorous physical activity was strongly associated with positive oral and general hygiene practices. ${ }^{8}$ However, our findings indicate that moderate, not vigorous, recreational activities were associated with positive oral health behaviors.

Overall, a positive oral health behavior does not necessitate positivism in all general health behaviors as suggested by Tada et al, who found that some relationships of oral health behaviors with general health behaviors were positive and some were not. ${ }^{9}$

\section{Limitations}

Although NHANES data are one of the most representative national data available, the study design is limited by sampling only a civilian, noninstitutionalized US population. Using a secondary data analysis design limited the number and types of variables available to select from, resulting in difficulty to decide if the outcome variables (i.e., oral health behaviors) included in this study were the most suitable for examining the association between general and oral health behaviors. In addition, it is inappropriate to conclude a causal relationship between these variables because of cross-sectional nature of the study design. There were a lot of missing values in some variables that hindered the inclusion of answers of many individuals who could increase the credibility of the results if their answers were available. Another challenge that compromises the credibility of the results is the self-reported nature of the survey, which increased the chance of recall bias, especially when questions ask about information of behaviors that occurred years ago.

\section{Public Health Implications}

Results of this study found that an individual's demographics has a major influence on oral health behaviors as do some general health behaviors (i.e., age at one's first sexual encounter, having a new sexual partner, mental health counseling, moderate-intensity sports, and computer use). Based on such findings, general and oral health promotion efforts should target risk behaviors common to both oral and general health. However, future research is recommended to examine more in depth the significant relationship found between such general health behaviors and oral health behaviors, to emphasize findings of this study and to help health promotion initiatives in designing effective programs.

\section{Funding}

None.

\section{Conflict of Interest}

None declared.

\section{References}

1 Söder B, Jin LJ, Klinge B, Söder PO. Periodontitis and premature death: a 16-year longitudinal study in a Swedish urban population. J Periodontal Res 2007;42(4):361-366

2 United States Department of Health and Human Services, Oral Health in America: A Report of the Surgeon General. Rockville, MD: National Institute of Dental and Craniofacial Research, National Institutes of Health; 2000

3 Holmlund A, Holm G, Lind L. Number of teeth as a predictor of cardiovascular mortality in a cohort of 7,674 subjects followed for 12 years. J Periodontol 2010;81(6):870-876

4 Imai S, Mansfield CJ. Oral health in North Carolina: relationship with general health and behavioral risk factors. N C Med J 2015;76(3):142-147

5 Vincent RR, Appukuttan D, Victor DJ, Balasundaram A. Oxidative stress in chronic periodontitis patients with type II diabetes mellitus. Eur J Dent 2018;12(2):225-231

6 Gupta N, Gupta ND, Gupta A, Goyal L, Garg S. The influence of type 2 diabetes mellitus on salivary matrix metalloproteinase-8 levels and periodontal parameters: a study in an Indian population. Eur J Dent 2015;9(3):319-323

7 Samnieng P, Ueno M, Zaitsu T, Shinada K, Wright FA, Kawaguchi Y. The relationship between seven health practices and oral health status in community-dwelling elderly Thai. Gerodontology 2013;30(4):254-261

8 Petersen PE, Jiang H, Peng B, Tai BJ, Bian Z. Oral and general health behaviours among Chinese urban adolescents. Community Dent Oral Epidemiol 2008;36(1):76-84

9 Tada A, Matsukubo T. Relationship between oral health behaviors and general health behaviors in a Japanese adult population. J Public Health Dent 2003;63(4):250-254

10 Hollister MC, Anema MG. Health behavior models and oral health: a review. J Dent Hyg 2004;78(3):6

11 Centers for Disease Control and Prevention (CDC). National Health and Nutrition Examination Survey: Survey Methods and Analytic Guidelines. Available at: https://wwwn.cdc.gov/ nchs/nhanes/analyticguidelines.aspx

12 Centers for Disease Control and Prevention (CDC). NHANES 2015-2016. Available at: https://wwwn.cdc.gov/nchs/nhanes/ ContinuousNhanes/Default.aspx?BeginYear=2015 
13 Centers for Disease Control and Prevention (CDC). National health and nutrition examination survey: demographic variables and sample weights. Available at: https://wwwn.cdc. gov/Nchs/Nhanes/2015-2016/DEMO_I.htm

14 Centers for Disease Control and Prevention (CDC). NHANES 2015-2016 data documentation, codebook, and frequencies: demographic variables and sample weights. Available at: https://wwwn.cdc.gov/Nchs/Nhanes/2015-2016/DEMO_I. htm\#Component_Description

15 Astrøm AN, Mbawalla H. Factor structure of health and oral health-related behaviors among adolescents in Arusha, northern Tanzania. Acta Odontol Scand 2011;69(5):299-309

16 Hobdell M, Johnson NW, Lalloo R, Myburgh N. Progress in policy issues to improve oral health in Africa. Oral Dis 2004;10(3):125-128

17 Payne BJ, Locker D. Relationship between dental and general health behaviors in a Canadian population. J Public Health Dent 1996;56(4):198-204

18 Manski, R. J. and Brown, E. Dental Use, Expenses, Private Dental Coverage, and Changes, 1996 and 2004. Rockville (MD):Agency for Healthcare Research and Quality; 2007. MEPS Chartbook No.17. Available at: http://www.meps.ahrq.gov/ mepsweb/data_files/publications/cb17/cb17.pdf

19 Sanders AE, Spencer AJ, Stewart JF. Clustering of risk behaviours for oral and general health. Community Dent Health 2005;22(3):133-140

20 Park YD, Patton LL, Kim HY. Clustering of oral and general health risk behaviors in Korean adolescents: a national representative sample. J Adolesc Health 2010;47(3):277-281

21 Jordão LMR, Malta DC, Freire MDC. Clustering patterns of oral and general health-risk behaviours in Brazilian adolescents: findings from a national survey. Community Dent Oral Epidemiol 2018;46(2):194-202

22 Peker I, Alkurt MT. Oral health attitudes and behavior among a group of Turkish dental students. Eur J Dent 2009;3(1):24-31

23 Dumitrescu AL, Dogaru BC, Duta C, Manolescu BN. Testing five social-cognitive models to explain predictors of personal oral health behaviours and intention to improve them. Oral Health Prev Dent 2014;12(4):345-355
24 Walker K, Jackson R. The health belief model and determinants of oral hygiene practices and beliefs in preteen children: a pilot study. Pediatr Dent 2015;37(1):40-45

25 Sivakumar V, Jain J, Battur H, Patil PU, Lingaraj S, Palliyal S. Exploring oral health beliefs and behaviour among Tibetan immigrants of Bylakkupe. Oral Health Prev Dent 2016;14(2):111-116

26 Kim HY, Kim Y, Hwang JM, Park YD. Oral health behaviours according to demographic characteristics in Korean adolescents: a national representative sample. Int Dent J 2011;61(3):168-173

27 Peltzer K, Pengpid S. Oral health behaviour and social and health factors in university students from 26 low, middle and high income countries. Int J Environ Res Public Health 2014;11(12):12247-12260

28 Imai S. Disparities in health status and health risk factors in Eastern North Carolina: data from the Behavioral Risk Factor Surveillance System, 2005-2009 aggregated. East Carolina University Web site. 2011. Available at: https://www.ecu.edu/ cs-dhs/chsrd/Pubs/upload/2015_Disparities_in_health_status_and_health_risk_factors_in_Eastern_NC.pdf

29 Saini R, Saini S, Sharma S. Oral sex, oral health and orogenital infections. J Glob Infect Dis 2010;2(1):57-62

30 Maida CA, Marcus M, Spolsky VW, Wang Y, Liu H. Socio-behavioral predictors of self-reported oral health-related quality of life. Qual Life Res 2013;22(3):559-566

31 Do KY, Lee ES, Lee KS. Association between excessive Internet use and oral health behaviors of Korean adolescents: a 2015 national survey. Community Dent Health 2017;34(3):183-189

32 Park S, Lee JH. Associations of Internet use with oral hygiene based on national youth risk behavior survey. J Korean Acad Child Adolesc Psychiatry 2018;29(1):26-30

33 Jiang H, Petersen PE, Peng B, Tai B, Bian Z. Self-assessed dental health, oral health practices, and general health behaviors in Chinese urban adolescents. Acta Odontol Scand 2005;63(6):343-352

34 Coulter ID, Heslin KC, Marcus M, et al. Associations of selfreported oral health with physical and mental health in a nationally representative sample of HIV persons receiving medical care. Qual Life Res 2002;11(1):57-70 